\title{
Sistem Pengaman Parkir dengan Visualisasi Jarak Menggunakan Sensor PING dan LCD
}

\author{
Dwi Putra Githa \\ Dosen Sistem Komputer \\ STMIK STIKOM Indonesia \\ Denpasar-Bali, Indonesia \\ dwiputragitha@gmail.com
}

\author{
Wayan Eddy Swastawan \\ Mahasiswa Sistem Komputer \\ STMIK STIKOM Indonesia \\ Denpasar-Bali, Indonesia \\ eddyswastawan@gmail.com
}

\begin{abstract}
Abstrak-Kebutuhan akan parkir mobil menjadi semakin sulit seiring meningkatnya jumlah kendaraan dan semakin sempitnya lahan. Terkadang seorang pengendara merasa kesulitan menghadapi situasi seperti ini, dikarenakan tidak adanya sistem peringatan yang mendeteksi jarak posisi parkir yang aman serta visualisasi jarak tersebut. Saat ini beberapa jenis mobil tertentu telah memiliki fitur yang telah ditambahkan yang dapat memudahkan proses parkir, seperti sensor ultrasonik yang dipasang di belakang mobil dengan menggunakan buzer sebagai indikator bunyi atau suara sebagai outputnya. Namun hal ini dirasa masih kurang, karena sensor parkir ini tidak dapat memberitahukan seberapa dekat jarak dengan halangan yang ada pada saat melakukan parki.
\end{abstract}

Komponen utama pendukung sistem ini adalah sensor ultrasonik, mikrokontroler, lcd display, buzer dan led. Sistem ini akan bekerja pada saat kendaraan akan melakukan parkir, dimana mikrokontroler akan memproses data dari sensor ultrasonik sehingga didapat suatu hasil yang nantinya akan dikirimkan ke lcd sebagai penampil jarak, buzer sebagai indikator peringatan berupa suara, dan led sebagai indikator peringatan berupa cahaya. Hasil pengujian dilakukan dilakukan dengan menjalankan sistem pengaman parkir dan sistem dapat berjalan dengan baik. Berdasarkan pada pengujian peringatan pertama, jarak rata-rata yang dideteksi sistem pengaman parkir adalah $20.5 \mathrm{~cm}$, pengujian kedua $11 \mathrm{~cm}$ dan pengujian ketiga $6.4 \mathrm{~cm}$.

Kata Kunci: sistem pengaman parkir, sensor ultrasonik, mikrokontroler, lcd

\section{PENDAHULUAN}

Perkembangan teknologi yang ada saat ini menghadirkan kemudahan-kemudahan bagi kehidupan manusia, salah satunya komputer. Saat ini komputer telah menjadi perangkat utama untuk memudahkan manusia dalam melakukan sesuatu. Perkembangan komputer tidak lepas dari peran dunia elektronika didalamnya. Dengan perkembangan elektronika maka secara langsung akan mendukung perkembangan komputer yang semakin canggih.

Dalam bidang transportasi, salah satu perkembangan teknologi dapat kita temukan dalam suatu sistem pengaman parkir pada mobil. Dahulu parkir dalam suatu tempat, baik gedung, tempat parkir supermarket, mall, dirumah dan yang lainnya memerlukan waktu dan tenaga yang tidak sedikit. Pengguna parkir harus susah-susah mencari tempat parkir yang nyaman, maju mundur mengatur posisi kendaraan dengan mengeluarkan kepala agar mobil tidak terbentur. Kurang efisien, membutuhkan waktu yang lama, keamanan juga belum tentu terjamin. Sebenarnya jika proses parkir tersebut dapat dibantu dengan suatu sistem yang lebih modern (otomatisasi sistem) akan sangat menguntungkan, baik itu bagi industri (industri otomotif), perusahaan pengelola parkir, pengguna parkir dan bagi pemilik kendaraan yang memiliki parkir pribadi dirumahnya.

Saat ini telah ada sistem pengamanan parkir yang terdapat pada mobil dengan seri dan tipe-tipe tertentu dengan menggunakan sensor ultrasonik. Umumnya sensor ultrasonik ini telah ada pada mobil keluaran terbaru. Sensor tersebut digabungkan dengan indikator suara, dimana sistem ini akan memberikan peringatan berupa suara saat mobil akan membentur sesuatu pada saat parkir. Harga mobil yang telah dilengkapi sistem pengaman parkir dengan sensor ini cukup lumayan mahal, karena tidak terdapat di semua seri maupun tipe. Selain itu kurang ada informasi mengenai jarak antara mobil dan penghalang. Padahal informasi terkait jarak sangat penting untuk memastikan posisi mobil tidak menabrak atau mengenai sesuatu.

Dari permasalahan diatas maka dilakukan penelitian mengenai perancangan dan 
pembangunan sistem pengaman parkir dengan visualisasi jarak menggunakan sensor PING dan LCD untuk menampilkan informasi jarak.

\section{SENSOR ULTRASONIK}

Menurut [1]," sensor ultrasonik adalah sensor pengukur jarak suatu objek ". Ultrasonik sering digunakan untuk keperluan mengukur jarak sebuah benda atau untuk mendeteksi halangan.Dalam dunia elektronika, ultrasonik biasanya dikemas dalam kit sensor ultrasonik yang di dalamnya terdapat receiver dan transmitter ultrasonik. Transmitter akan mengirimkan gelombang, kemudian receiver akan menerima pantulan gelombang tersebut. Jarak sebuah benda dapat diketahui dengan menghitung selisih antara waktu kirim gelombang dan waktu terima. Lama waktu sejak gelombang dikirimkan hingga gelombang kembali ke sensor inilah yang akan dihitung dan diproses oleh mikrokontroler, nantinya akan di representasikan jaraknya kemudian akan ditampilkan pada LCD dan untuk menghasilkan suara pada buzer. Sensor ultrasonik yang cukup terkenal di kalangan robotika adalah sensor ultrasonik Ping))) dari Parallax. Dengan ukurannya yang cukup kecil $(2,1 \mathrm{~cm} \times 4,5 \mathrm{~cm})$, sensor ini dapat mengukur jarak antara $3 \mathrm{~cm}$ sampai $300 \mathrm{~cm}$. Tetapi sayang harganya relatif mahal untuk pasaran Indonesia. Gambar 1 menunjukan foto sensor Ping))) Parallax. Cara kerja sensor Ping))) adalah sensor transmiter mengirimkan sinyal ultrasonik ke benda yang ada didepannya. Kemudian sinyal dipantulkan oleh benda dan diterima oleh sensor receiver seperti yang ditunjukan oleh gambar 2 .

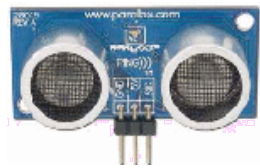

Gambar 1. Ping))) Paralax Ultrasonic Range Finder

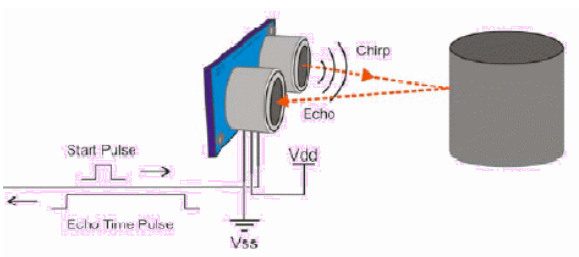

Gambar 2. Ilustrasi cara kerja Sensor Ping)))

\section{MIKROKONTROLER}

Menurut [1], " mikrokontroler adalah salah satu bagian dari sebuah sistem komputer yang berfungsi sebagai control rangkaian ". Meskipun mempunyai bentuk yang jauh lebih kecil dari suatu komputer pribadi dan komputer mainframe, mikrokontroler dibangun dari elemen-elemen dasar yang sama. Secara sederhana, komputer akan menghasilkan output spesifik berdasarkan sinyal input yang diterima dan program dikerjakan. Seperti umumnya komputer, mikrokontroler adalah alat yang mengerjakan instruksi-instruksi yang diberikan kepadanya.

Menurut [2], "Pemrograman mikrokontroler merupakan dasar dari prinsip pengontrolan kerja robot, dimana orientasi penerapan mikrokontroler adalah untuk mengendalikan suatu sistem berdasarkan informasi input yang diterima, lalu diproses oleh mikrokontroler, dan dilakukan aksi pada bagian output sesuai program yang telah ditentukan sebelumnya".

Pada umumnya mikrokontroler memiliki instruksi manipulasi bit, akses ke I/O secara langsung dan mudah, dan proses interrupt yang cepat dan efisien. Dengan kata lain mikrokontroler adalah "Solusi satu Chip" yang secara drastis mengurangi jumlah komponen dan biaya. Lebih lanjut, mikrokontroler merupakan sistem komputer yang mempunyai satu atau beberapa tugas yang sangat spesifik, berbeda dengan personal computer ( PC ) yang memiliki beragam fungsi. Gambar 3 merupakan contoh mikrokontroler.

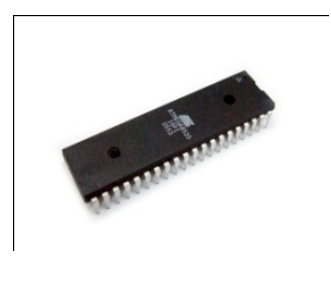

Gambar 3. Mikrokontroller

IV.LIQUID CRISTAL DISPLAY (LCD)

Sesuai dengan pendapat[1] mengatakan bahwa LCD sering digunakan sebagai penampil karakter atau gambar sebuah sistem digital atau mikrokontroler.LCD (Liquid Crystal Display) adalah suatu jenis media tampilan yang mengubah kristal cair sebagai penampil utama. LCD dapat memunculkan tulisan karena terdapat banyak pixel yang terdiri dari satu buah kristal cair sebagai sebuah titik cahaya.

Walau disebut sebagai titik cahaya, namun kristal cair ini tidak memancarkan cahaya sendiri. Sumber cahaya di dalam sebuah perangkat LCD adalah sebuah lampu nenon di bagian belakang susunan kristal cair tersebut. Titik cahaya inilah yang membentuk tampilan citra. Kutub kristal cair yang dilewati arus listrik akan berubah karena pengaruh polarisasi medan magnet yang timbul. 
Oleh karena itu, hanya beberapa warna saja yang diteruskan sedangkan warna lainnya tersaring.

Dalam hal ini digunakan LCD dengan banyak karakter $2 \times 16$. Karena LCD $2 \times 16$ ini biasa digunakan sebagai penampil karakter atau data pada sebuah rangkaian digital atau mikrokontroler.

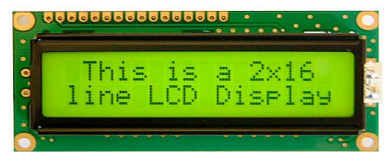

Gambar 4. Modul LCD Karakter 2x16

\section{CODEVISIONAVR}

Menurut [3], “ CodeVisionAVR adalah compiler $\mathrm{C}$, yang telah dilengkapi dengan fasilitasIntegrated Development Environtment (IDE) dan didesain agar dapat menghasilkan kode program secara otomatis untuk mikrokontroler Atmel AVR. Program ini dapat berjalan dengan menggunakan sistem operasi Windows 2000, XP, Vista dan Window 7."

CodeVisionAVR menyediakan sebuah editor yang di desain untuk menghasilkan program C secara otomatis untuk mikrokontroler AVR. Integrated Development Environtment (IDE) telah dilengkapi dengan fasilitas pemrograman chip melalui metode In-System Programming sehingga dapat secara otomatis mentransfer file program kedalam chip mikrokontroler AVR setelah sukses di kompilasi.

Software In-System Programmer didesain untuk bekerja ketika dihubungkan dengan development board STK500, STK600, AVRISP, AVRISP mkII, AVR Dragon, AVRProg (AVR910 application note), Atmel JTAGICE mkII, kanda System STK200+STK300, Dontronics DToo6, Vogel Elektonik VTEC-SIP, Futurlec JRAVR and MicroTronics ATCPU, dan Mega2000.

\section{PERANCANGAN SISTEM}

Sistem pengaman parkir adalah suatu sistem yang bertujuan untuk membantu pengendara mobil pada saat parkir. Sistem ini bekerja dengan mendeteksi halangan yang ada di depan maupun belakang mobil kemudian sistem akan memvisualisasikan jarak dengan halangan tersebut. Sistem ini diharapkan dapat mempermudah pengendara memantau jarak mobil mereka dengan halangan yang ada di belakang maupun di depan pada saat parkir. Dalam perancangan dan implementasinya, masalah yang harus diatasi adalah sistem penghitung jarak sehingga lcd dapat menampilkan jarak sesungguhnya, arsitektur hardware yang meliputi perangkat elektronik, serta organisasi software untuk basis pengetahuan dan pengendalian secara waktu nyata serta mengimplementasikan suatu Sistem Pengaman Parkir dengan menggunakan mikrokontroler ATmega16, sensor Ultrasonik dan LCD display. Basis pengetahuan sistem ini berisi pengkodean aksi yang harus dilakukan oleh sistem berdasarkan informasi dari sensor.

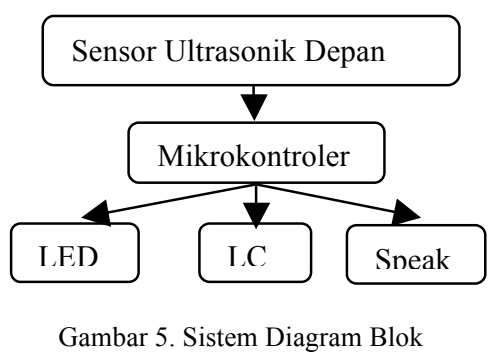

Blok diagram pada gambar 5 menunjukan cara kerja sistem keseluruhan. Dimana mikrokontroler menerima data dari sensor yang ada di belakang maupun didepan, untuk prioritas adalah sensor yang paling dekat dengan halangan. Selanjutnya data akan kirimkan ke indikator suara sebagai peringatan dan $l c d$ sebagai display jarak. Secara garis besar sistem pengaman parkir ini terdiri dari dua bagian,yaitu perangkat keras (Hardware) dan perangkat lunak (software).Perangkat keras terdiri dari Sensor Ultrasonik,Mikrokontroler, LCD, serta buzer dan perangkatlunak terdiri dariintruksiintruksi yang telah diinputkan ke dalam mikrokontroler. Sebelumnya telah dijelaskan, program yang digunakan adalah bahasa $\mathrm{C}$ dengan menggunakan CodeVisionAVR untuk download program ke mikrokontroler. Gambar 6 merupakan diagram alir dari cara kerja sistem pengaman parkir. 


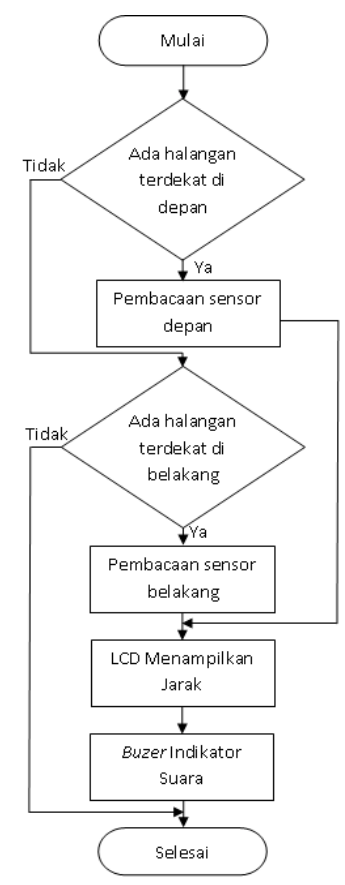

Gambar 6. Diagram Alir Cara Kerja Sistem Pengaman Parkir

Keterangan :

1. Cara kerja sistem ini yaitu pertama-tama sensor akan mendeteksi halangan yang terdekat.

2. Jika terdapat halangan di depan, maka akan dilakukan proses pembacaan atau pendeteksian halangan di sensor bagian depan.Kemudian jarak akan ditampilkan ke lcd kemudian ke buzer dan selesai. Pendeteksian dibagi menjadi tiga peringatan, peringatan pertama jarak 11-20 $\mathrm{cm}$, peringatan kedua $6-10 \mathrm{~cm}$ dan peringatan ketiga $<5 \mathrm{~cm}$.

3. Jika tidak terdapat halangan di depan, maka kemudian dilakukan proses selanjutnya, yaitu proses pembacaan atau pendeteksi halangan di sensor bagian belakang.

4. Jika terdapat halangan di belakang, maka akan dilakukan proses pembacaan atau pendeteksian halangan di sensor bagian belakang. Kemudian jarak akan ditampilkan ke lcd kemudian ke buzer dan selesai. Pendeteksian dibagi menjadi tiga peringatan sama seperti sensor pada bagian depan.

5. Jika tidak terdapat halangan di belakang, maka sistem akan memulai dari proses awal proses pendeteksian halangan, dan proses di atas akan terus berulang.

Gambar 7 merupakan skema dari sistem pengaman parkir yang dibangun.

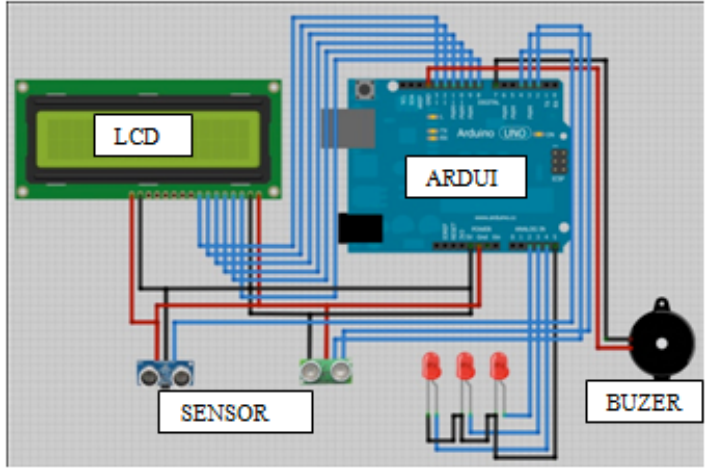

Gambar 7. Skema Rangkaian Komponen Sistem Pengaman Parkir

Keterangan :

1. Pin digital 8-3 berfungsi untuk menampilkan karakter di $l c d$.

2. Pin Gnd pada lcd berfungsi sebagai ground.

3. Pin $5 \mathrm{~V}$ pada $l c d$ berfungsi sebagai daya agar $l c d$ dapat menyala. Pada $l c d$ dibutuhkan 2 daya, yang pertama berfungsi sebagai daya untuk karakter dan yang kedua sebagai daya latar dari $l c d$ itu sendiri.

4. Pin Gnd pada buzer berfungsi sebagai ground.

5. Pin digital 7 pada buzer berfungsi sebagai output.

6. Pin analog 2-5 pada led berfungsi sebagai output.

7. Pin digital 2 pada sensor berfungsi sebagai trigger atau penerima sinyal pantulan.

8. Pin digital digital 3 pada sensor belakang berfungsi sebagai echo atau pengirim sinyal yang nantinya sinyal tersebut akan dipantulkan dan diterima oleh trigger.

9. Pin Gnd pada sensor belakang berfungsi sebagai ground.

10. Pin $5 \mathrm{~V}$ pada sensor belakang berfungsi sebagai daya.

11. Pin digital 4 pada sensor depan berfungsi sebagai transmitter dan receiver.

12. Pin Gnd pada sensor depan berfungsi sebagai ground.

13. Pin $5 \mathrm{~V}$ pada sensor depan berfungsi sebagai daya.

\section{PENGUJIAN}

Setelah melakukan perancangan dan pembuatan sistem pengaman parkir, maka 
dilanjutkan dengan pengujian. Hal ini bertujuan agar sistem dapat bekerja sebagaimana mestinya. Pengujian dilakukan tiga kali dengan menguji tiga jarak yang berbeda untuk masing-masing peringatan yang ditampilkan. Pengujian dilakukan dengan lima kali percobaan untuk masing-masing peringatan. Prosedur pengujian dilakukan dengan tahapan:

1. Sistem pengaman parkir didekatkan ke halangan secara perlahan sampai peringatan muncul untuk ketiga peringatan yang ada.

2. Mengukur dan mencatat jarak riil antara sistem pengaman parkir dengan halangan untuk ketiga peringatan yang ada.

3. Mencatat jarak yang ditampilkan di LCD untuk ketiga peringatan yang ada.

Hasil dari pengujian dapat dilihat pada tabel 1,2 dan 3 .

TABel 1. Pengujian Peringatan Pertama

\begin{tabular}{|c|c|c|}
\hline Percobaan & Jarak & LCD \\
\hline 1 & $21.8 \mathrm{~cm}$ & $19 \mathrm{~cm}$ \\
\hline 2 & $21 \mathrm{~cm}$ & $19 \mathrm{~cm}$ \\
\hline 3 & $20.5 \mathrm{~cm}$ & $20 \mathrm{~cm}$ \\
\hline 4 & $20.3 \mathrm{~cm}$ & $19 \mathrm{~cm}$ \\
\hline 5 & $19 \mathrm{~cm}$ & $20 \mathrm{~cm}$ \\
\hline Rata - rata & $20.5 \mathrm{~cm}$ & $19 \mathrm{~cm}$ \\
\hline
\end{tabular}

TABel2. Pengujian PeRingatan KeduA

\begin{tabular}{|c|c|c|}
\hline Percobaan & Jarak & LCD \\
\hline 1 & $11 \mathrm{~cm}$ & $9 \mathrm{~cm}$ \\
\hline 2 & $11.3 \mathrm{~cm}$ & $9 \mathrm{~cm}$ \\
\hline 3 & $11.2 \mathrm{~cm}$ & $9 \mathrm{~cm}$ \\
\hline 4 & $10.5 \mathrm{~cm}$ & $10 \mathrm{~cm}$ \\
\hline 5 & $11 \mathrm{~cm}$ & $9 \mathrm{~cm}$ \\
\hline Rata - rata & $11 \mathrm{~cm}$ & $9 \mathrm{~cm}$ \\
\hline
\end{tabular}

TABel3. Pengujian Peringatan Ketiga

\begin{tabular}{|c|c|c|}
\hline Percobaan & Jarak & LCD \\
\hline 1 & $6.1 \mathrm{~cm}$ & $5 \mathrm{~cm}$ \\
\hline 2 & $6.5 \mathrm{~cm}$ & $5 \mathrm{~cm}$ \\
\hline 3 & $6.3 \mathrm{~cm}$ & $5 \mathrm{~cm}$ \\
\hline 4 & $6.4 \mathrm{~cm}$ & $5 \mathrm{~cm}$ \\
\hline 5 & $7 \mathrm{~cm}$ & $5 \mathrm{~cm}$ \\
\hline Rata - rata & $6.4 \mathrm{~cm}$ & $5 \mathrm{~cm}$ \\
\hline
\end{tabular}

Dari hasil pengujian yang dilakukan dapat disimpulkan untuk pengujian peringatan pertama keakuratan dari sistem pengaman parkir adalah $\frac{19}{20,5} \times 100 \%=92,68 \%$. Untuk pengujian peringatan kedua keakuratan dari sistem pengaman parkir adalah $\frac{9}{11} \times 100 \%=81,8 \%$ dan untuk pengujian peringatan ketiga keakuratan sistem pengaman parkir adalah $\frac{5}{6,4} \times 100 \%=78,12 \%$.

Keakuratan sistem pengaman parkir tidak dapat $100 \%$ akurat disebabkan oleh pembacaan sensor Ping))) yang tidak bisa $100 \%$ akurat. Ketidakakuratan pembacaan sensor disebabkan oleh adanya noise. Modul sensor Ping))) bekerja berdasarkan prinsip pemantulan gelombang ultrasonik, terkadang pantulan gelombang ultrasonik menjadi tidak periodik dan menyebabkan hasil pengukuran tidak akurat. Selain itu, kesalahan pengukuran juga dapat terjadi karena pembulatan perhitungan pada saat pembuatan program.

\section{SIMPULAN}

Berdasarkan hasil penelitian sistem pengaman parkir dapat ditarik beberapa kesimpulan seperti :

1 Tahapan perancangan dan pembangunan sistem pengaman parkir dimulai dari perakitan komponen perangkat keras dilanjutkan dengan pembuatan kode program untuk dimasukkan kedalam mikrokontroler menggunakan bahasa C.

2 Sistem pengaman parkir ini dibangun dengan menggunakan mikrokontroler, buzer, LCD display, dan 2 buah sensor ultrasonik yang berada pada depan dan belakang kendaraan.

3 Pada pengujian peringatan pertama, keakuratan dari sistem pengaman parkir adalah $92,68 \%$. Pada pengujian peringatan kedua, keakuratan dari sistem pengaman parkir adalah $81,8 \%$. Pengujian peringatan ketiga, keakuratan dari sistem pengaman parkir adalah $78,12 \%$.

4 Ketidakakuratan sistem pengaman parkir dalam membaca jarak disebabkan oleh adanya noise saat pembacaan sensor Ping))).

\section{REFERENSI}

[1] Arifianto, Deni, 2011. Kamus Komponen Elektronika. Jakarta: Kawan Pustaka.

[2] Budiharto, Widodo. 2010. Robotika Teori dan Implementasi. Yogyakarta: Andi

[3] Rangkuti, Syahban. 2011. Mikrokontroler ATMEL AVR ( ISIS PROTEUS dan CodeVisionAVR ). Bandung: Informatika 